\title{
Factors Associated with Psychiatrist Opt-out from US Medicare: an Observational Study
}

\author{
Jiani Yu, Ph.D. ' , Anupam B. Jena, M.D., Ph.D. ${ }^{2,3,4}$, Pinar Karaca Mandic, Ph.D. 4,5, and \\ Ezra Golberstein, Ph.D.'
}

'Division of Health Policy and Management, University of Minnesota School of Public Health, Minneapolis, MN, USA; ${ }^{2}$ Department of Health Care Policy, Harvard Medical School, Boston, MA, USA; ${ }^{3}$ Department of Medicine, Massachusetts General Hospital, Boston, MA, USA; ${ }^{4}$ National Bureau of Economic Research, Cambridge, MA, USA; ${ }^{5}$ Department of Finance, University of Minnesota Carlson School of Management, Minneapolis, MN, USA.

BACKGROUND: Concerns exist about availability and access to psychiatric services in the USA. For Medicare beneficiaries, one impediment to psychiatric services is the extent to which psychiatrists have opted out of the Medicare program.

OBJECTIVE: This study describes geographic variation in rates that psychiatrists opt out of Medicare, and assesses physician-level and geographic-level predictors of opt-out. DESIGN: Retrospective cross-sectional analysis of data describing psychiatrists' opt-out status as of March 2017 linked to data on psychiatrist location, psychiatrist characteristics (obtained from a comprehensive US physician database), and market area-level characteristics.

PARTICIPANTS: 27,838 psychiatrists in the USA

MAIN MEASURES: Whether a psychiatrist had opted out of Medicare as of March 2017.

KEY RESULTS: Overall, 7.0\% of psychiatrists (1940/27,838) opted out of Medicare as of March 2017. Opt-out rates varied substantially across states and within states. Physician-level factors independently associated with opt-out included: older age (psychiatrists > 65years were 2.6 percentage points more likely to opt vs. psychiatrists < 35 years old, $p=0.03$ ), greater years of experience, female gender (female psychiatrists were 2.6 percentage points more likely to opt out than male psychiatrists, $p<0.001$ ), graduation from a top-20 ranked medical school (1.7 percentage points more likely to opt out of Medicare, $p<0.001$ ), and domestic medical graduate (domestic graduates were 7.3 percentage points more likely to opt out of Medicare vs. foreign graduates, $p<0.001)$. Adjusting for other individualand geographic-level factors, psychiatrists who practiced in areas with more psychiatrists per Medicare beneficiary were less likely to opt out $(p<0.001)$.

CONCLUSIONS: The overall likelihood that psychiatrists opt out of Medicare is significant and varies considerably across regions and by characteristics of psychiatrists.

Prior Presentation A preliminary version of this research was presented as a poster at the 2018 AcademyHealth Annual Research Meeting, June 24-26, 2018, Seattle, WA.

Electronic supplementary material The online version of this article (https://doi.org/10.1007/s11606-019-05246-6) contains supplementary material, which is available to authorized users.

Received October 2, 2018

Revised April 11, 2019

Accepted July 3, 2019

Published online August 16, 2019
KEY WORDS: psychiatry; Medicare; workforce; access to care.

J Gen Intern Med 34(11):2460-6

DOI: $10.1007 / \mathrm{s} 11606-019-05246-6$

(c) Society of General Internal Medicine 2019

\section{INTRODUCTION}

Concerns about the availability of mental health providers have existed for years. Seventy-seven percent of US counties were estimated to have a severe shortage of prescribing mental health professionals in $2006 .{ }^{1}$ In 2010 , only $55 \%$ of officebased psychiatrists accepted new patients with private insurance and psychiatrists were less likely to accept patients with private insurance, Medicare, or Medicaid than other physician specialties. ${ }^{2}$ More recent data from the Affordable Care Act's (ACA) private health insurance marketplaces show that mental health providers are less likely to participate in insurance networks than primary care providers. ${ }^{3}$

Mental health problems are particularly important issues among the elderly Medicare population and the under- 65 population that qualifies for Medicare through disability. Yet, limited information exists on the available supply of psychiatrists in the Medicare program and factors associated with availability. This lack of evidence is especially important given recent Medicare policy changes to reduce out-ofpocket costs for outpatient mental health services to be at parity with comparable general medical services. ${ }^{4}$ These policy changes may increase demand for specialty mental health care among Medicare beneficiaries, although most evidence to date suggests that mental health parity has not substantially increased mental health service use. ${ }^{5}$

In any given health care market, the supply of physicians available to treat Medicare beneficiaries depends on the number of physicians per capita in that market and the proportion of physicians who choose to "opt out" of the Medicare program. The primary reason that physicians opt out of Medicare is to retain the ability to charge fees to Medicare patients that exceed the standard Medicare fee. In general, few providers choose to opt out of Medicare - in 2016, 0.7\% of all physicians chose to opt out of Medicare ${ }^{6}$ - but rates of opt-out are considerably higher in psychiatry than in other physician 
specialties. Psychiatrists comprise only $4.4 \%$ of physicians nationally, but account for $38.1 \%$ of physicians who opt out of Medicare. ${ }^{6,7}$ However, psychiatrist characteristics that are associated with opt-out, the extent of geographic variations, and the role of local market characteristics in psychiatrist optout are unknown. For example, more-experienced psychiatrists may be more likely to opt out, if their positive reputation allows them to charge fees above Medicare rates. Similarly, if medical school ranking proxies for quality, psychiatrists who graduated from higher ranked medical schools may be more likely to opt out. At the local market level, a limited supply of psychiatrists relative to demand may increase opt-out if psychiatrists are able to collect higher non-Medicare fees.

In this study, we combined data from Medicare with geographic data on local health care market characteristics and a comprehensive database of physician characteristics. We investigated the extent of geographic variation in rates of psychiatrist opt-out of Medicare and studied which area-level and psychiatrist-level factors are associated with psychiatrist optout of Medicare.

\section{METHODS Data and Sample Construction}

We merged the Centers for Medicare and Medicaid Services' (CMS) published list of providers who opted out of Medicare as of March 2017, ${ }^{8}$ with a cross-sectional database of US physicians assembled by Doximity. Doximity (https://www. doximity.com/about/company) is an online social networking platform for US physicians, and as of 2017, approximately $70 \%$ of all US physicians were registered members. The Doximity database includes comprehensive information on physician characteristics, described below, for all US physicians with active National Provider Identifiers (NPIs), both those who are registered members of the service as well as those who are not. This information is obtained through multiple sources and data partnerships, including the National Plan and Provider Enumeration System (NPPES) National Provider Identifier Registry, state medical boards, specialty societies such as the American Board of Medical Specialties, and collaborating hospitals and medical schools. Although many physicians are registered with the service, the data that we used do not come from self-reports of these physicians to Doximity, but rather administratively reported data in the sources listed above, and the database that we analyzed was not restricted to registered members, but instead included all practicing psychiatrists in the USA. The database has been used and validated in several prior studies. ${ }^{9-12}$

Physicians were matched between the Medicare and Doximity databases using the NPI. The Doximity database included 582,867 providers as of March 2017 and served as the denominator in our analysis of psychiatrist opt-out status. This combined dataset was then merged with the NPPES, updated March 2017, in order to identify and retain only active physicians, ${ }^{13}$ yielding a dataset of 582,837 active physicians. Psychiatrists were identified by first using the specialty provided by Doximity, and then searching for additional mental health specialists by merging on the CMS Taxonomy Crosswalk to the Healthcare Provider Taxonomy Code provided in the NPPES ${ }^{7}$ (searching in the grouping, specialization and classification variables for behavioral health, counseling and mental health specialists, psychiatrists, and psychologists). We also searched through the provider type variable in NPPES for psychiatrists. Child psychiatrists were excluded due to our focus on Medicare. After removing all non-mental health specialties and physicians without a Doximity record from the dataset, our dataset included 35,469 psychiatrists. The final study sample included all psychiatrists in the Doximity data that we were able to match with a Hospital Referral Region (HRR), as defined by the Dartmouth Atlas of Health Care, and a Primary Care Service Area (PCSA), as defined by the Health Resources and Services Administration, using their most recently updated practice zip codes from 2017. Among all of the variables in our analysis, only three variables contained some missing data. These were age $(8.8 \%$ missing $)$, whether the provider attended a foreign medical school (12.8\% missing), and the number of decades since graduation $(7.9 \%)$. We used listwise deletion and included only records that contained no missing variables in the final sample. Our final sample consisted of 27,838 psychiatrists, located within 306 HRRs and 2935 PCSAs.

\section{Analysis}

Our analysis consisted of two parts. The first part was a descriptive analysis of the geographic variation in unadjusted Medicare opt-out rates for psychiatrists, where we constructed average Medicare opt-out rates for psychiatrists at the HRR and state levels and presented the data in maps to illustrate geographic variation in Medicare opt-out rates. Although we do not consider HRRs as an ideal geographic unit for studying psychiatrist opt-out, we aggregated to the HRR level for the graphical presentation. We use HRRs because they represent meaningful health care markets ${ }^{14}$ that are large enough to discern graphically, while avoiding definitions of markets with very few psychiatrists that would have noisy measures of the percent opting out. In the online Appendix figures, we show analogous maps of variation in the number of psychiatrists who accept Medicare payment per capita.

The second part of our analysis was a multivariable logistic regression, described below, to examine the relationship between psychiatrist-level and area-level characteristics and psychiatrist opt-out. In this analysis, we used the PCSA as our preferred measure of geographic area. ${ }^{15}$ Though designed to measure service areas and markets for primary care, we considered the PCSA to be a reasonable proxy for markets for psychiatric services, and preferable to the HRR which can encompass a very large geographic area that was initially designed to represent markets for tertiary hospital services. 
The Doximity data included physician-level variables related to education, including age, gender, medical school attended and year of graduation, whether the provider graduated from a foreign medical school, and years of practice experience. We constructed five age categories (34 years or under (reference category), 35-44 years, 45-54 years, 5564 years, 65 years or over), and created an indicator for whether the medical school from which a psychiatrist graduated was ranked in the top-20 US schools based on the US News and World Report's 2017 medical school rankings. ${ }^{16}$

We used the PCSA file from the Health Resources and Services Administration ${ }^{17}$ to create PCSA-level demographic and socio-economic measures: the proportion of the 65 and older who were ages $65-74$ years, $75-84$ years, and 85 years and older; the Medicare Advantage participation rate; the proportion of the population that is a racial or ethnic minority; the percentage of individuals with a Bachelor's degree or higher; and the percentage of individuals 18 years or over living below the federal poverty line. We measured the supply of psychiatrists at the PCSA level by constructing a variable for the number of psychiatrists per 100 Medicare beneficiaries. We also created a measure of the percent of Medicare beneficiaries who were dually eligible for Medicare and Medicaid, using the 2015 Medicare Public Use file. ${ }^{18}$ This measure was unavailable at the PCSA level, so we measured it at the HRR level. ${ }^{19}$

We estimated the association between physician-level and area-level characteristics and the likelihood of that a physician opted out of Medicare, using a mixed effects logistic regression model of opt-out status. The mixed effects logistic regression model includes random effects for the geographic markets (HRRs and PCSAs), to account for the shared variance among individual psychiatrists within health care markets. ${ }^{20}$ The unit of analysis was the psychiatrist, and the outcome of interest, opt-out of Medicare, took on the value of 1 if the psychiatrist had currently opted out of Medicare (as of March 2017) and 0 otherwise.

The covariates, listed in Table 1, were selected based on a conceptual model from economics about how providers choose how many patients to see when patients differ in insurance status and accompanying payment levels. ${ }^{21}$ Psychiatrists with characteristics that may signal higher quality to patients (for example, greater experience or more prestigious training) may be more likely to opt out because Medicare patients would be more willing to pay higher fees for those psychiatrists. Areas with more Medicare beneficiaries with high levels of income or wealth may have greater willingness-to-pay for psychiatrist services, which would increase the likelihood that a psychiatrist would opt out of Medicare. And, if the supply of psychiatrists in an area were low relative to the population, then psychiatrists would in theory be more likely to opt out of Medicare since less competition would make it more feasible to charge higher fees.

The cross-sectional logistic regression model adjusts for a number of factors, but is unable to account for all differences across areas that may affect psychiatrists' likelihood of opting out of Medicare, including the supply of care that may substitute for psychiatric care, local treatment styles of physicians, and the community-level demand for mental health services. In addition, we cannot identify why certain areas have different numbers of psychiatrists. As such, the multivariable logistic regression results should not be interpreted as causal estimates.

The study was approved as exempt from review by the institutional review board of the University of Minnesota. Analysis was performed using Stata Version 14. The 95\% confidence intervals around reported estimates reflected 0.025 in each tail or $p \leq 0.05$.

\section{RESULTS}

\section{Characteristics of Psychiatrists}

The final study sample included 27,838 psychiatrists. Of these, $1940(7.0 \%)$ had opted out of Medicare payment. The individual-level summary statistics are in panel A of Table 1. Among the non-opt-out psychiatrists, $68.2 \%$ of the samples were male, whereas only $61.6 \%$ of the opting out psychiatrists were male. In addition, age was greater among psychiatrists who opted out of Medicare compared with psychiatrists who did not opt out. For example, among psychiatrists who opted out, $64.6 \%$ were 55 years or older compared with $49.5 \%$ of psychiatrists in the non-opt-out sample. The opt-out sample also contained relatively more psychiatrists that had four decades or more years of experience $(59.2 \%)$ compared with the non-opt-out sample $(46.3 \%)$ and more individuals that graduated from a top-20 medical school (23.0\% vs. $10.1 \%)$. Finally, there were fewer foreign medical graduates in the opt-out sample $(11.1 \%)$ compared with the non-opt-out sample $(33.2 \%)$.

Area-level characteristics of the sample are shown in panel B of Table 1. Average PCSA-level age distribution among the elderly was similar between psychiatrists who did and did not opt out of Medicare. Psychiatrists who opted out of Medicare payment worked in areas with a lower percentage of Medicare beneficiaries enrolled in Medicare Advantage $(p<0.001)$, in areas with a lower percentage of non-white Medicare beneficiaries $(p=0.006)$, and in areas with a higher percentage of Medicaid dually eligible beneficiaries $(p<0.001)$. Psychiatrists who opted out of Medicare payment worked in areas with fewer psychiatrists per Medicare beneficiary $(p=0.07)$, fewer people living below the poverty line $(p<0.001)$, and more adults with a college degree or more education $(p<0.001)$.

\section{Geographic Variation in Opt-out}

The unadjusted proportion of psychiatrists who opted out of Medicare varied widely across states (Fig. 1). For instance, no psychiatrists in Vermont or North Dakota opted out of 
Table 1 Characteristics of Study Population

\begin{tabular}{|c|c|c|c|}
\hline & $\begin{array}{l}\text { Full sample } \\
(n=27,838)\end{array}$ & $\begin{array}{l}\text { Opt-out psychiatrists } \\
(n=1940)\end{array}$ & $\begin{array}{l}\text { Non-opt-out psychiatrists } \\
(n=25,898)\end{array}$ \\
\hline \multicolumn{4}{|l|}{ Panel A. Psychiatrist-level variables (\%) } \\
\hline Gender, male & 67.7 & $61.6 *$ & $68.2 *$ \\
\hline Age category: $<35$ & 4.1 & $2.6^{*}$ & $4.3^{*}$ \\
\hline Age category: $35-44$ & 20.8 & $14.2 *$ & $21.3 *$ \\
\hline Age category: $45-54$ & 24.4 & $18.7 *$ & $24.8^{*}$ \\
\hline Age category: $55-54$ & 27.2 & $29.0 *$ & $27.0 *$ \\
\hline Age category: $>65$ & 23.4 & $35.6^{*}$ & $22.5^{*}$ \\
\hline Graduated from a foreign medical school program & 31.7 & $11.1^{*}$ & $33.2 *$ \\
\hline Graduated from a top- 20 medical school & 11.0 & $23.0 *$ & $10.1 *$ \\
\hline Decade since medical school graduation -1 & 5.0 & $3.5^{*}$ & $5.1 *$ \\
\hline Decade since medical school graduation -2 & 22.4 & $16.1 *$ & $22.9 *$ \\
\hline Decade since medical school graduation-3 & 25.5 & $21.3 *$ & $25.8^{*}$ \\
\hline Decade since medical school graduation -4 & 25.8 & $27.7 *$ & $25.6^{*}$ \\
\hline Decade since medical school graduation -5 & 15.6 & $21.7^{*}$ & $15.1^{*}$ \\
\hline Decade since medical school graduation -6 & 5.3 & $8.9^{*}$ & $5.1 *$ \\
\hline Decade since medical school graduation -7 & 0.5 & $0.9^{*}$ & $0.5^{*}$ \\
\hline \multicolumn{4}{|l|}{ Panel B. Geographic-level variables (\%) } \\
\hline \multicolumn{4}{|l|}{ PCSA-level variables } \\
\hline Medicare beneficiaries in Medicare Advantage (\%) & 27.2 & $24.1 *$ & $27.5^{*}$ \\
\hline Elderly beneficiaries between the ages of $65-74(\%)$ & 53.1 & 53.1 & 53.1 \\
\hline Elderly beneficiaries between the ages of $75-84(\%)$ & 32.4 & $31.9 *$ & $32.5^{*}$ \\
\hline Elderly beneficiaries aged 85 and older $(\%)$ & 14.5 & $15.0 *$ & $14.5^{*}$ \\
\hline Non-white population $(\%)$ & 30.6 & $29.4 *$ & $30.7 *$ \\
\hline Population with a Bachelor's degree - age 18 or older $(\%)$ & 24.7 & $35.3 *$ & $23.9^{*}$ \\
\hline Population living below the federal poverty level —age 18 or older $(\%)$ & 14.3 & $11.6^{*}$ & $14.5^{*}$ \\
\hline Number of psychiatrists per 100 Medicare beneficiaries & 0.6 & 0.5 & 0.6 \\
\hline \multicolumn{4}{|l|}{ HRR-level variables } \\
\hline Dual eligibles $(\%)$ & 11.1 & $13.8^{*}$ & $10.9 *$ \\
\hline
\end{tabular}

Sources: Data on opt-out status from the Center for Medicare and Medicaid Services, March 2017, CMS National Plan and Provider Enumeration System, CMS Geographic Variation Public Use File, Dartmouth Atlas of Health Care - End-of-life inpatient care, Percent of Medicare Beneficiaries Eligible for Medicaid, PCSA data download, Doximity data, US News and World Report's "Best Medical Schools: Research Rankings," US Census Bureau - Metropolitan and Micropolitan Statistical Area Datasets

$*$ Difference is statistically significant at $p<0.05$

Medicare, whereas the proportions opting out in New York and Washington, DC were $13 \%$ and $29 \%$, respectively. Similarly, the unadjusted proportion of psychiatrists opting out varied substantially across HRRs (Fig. 2). In $37 \%$ of HRRs, no psychiatrists opted out of Medicare. However, in $11 \%$ of HRRs, over $10 \%$ of psychiatrists opted out of Medicare. Optout rates also varied substantially within states. For example, California and New York were two of the states with high optout rates. However, within California, where the average optout rate was $10.2 \%$, HRR-level opt-out rates ranged from 0 to $31 \%$. Similarly, within New York, where the average opt-out rate was $13 \%$, HRR-level opt-out rates ranged from 0 to $23 \%$.

\section{Factors Associated with Psychiatrist Opt-out of Medicare}

After adjusting for provider-level and area-level dependent variables, several characteristics were significantly independently associated with the likelihood of opt-out of Medicare payment (Table 2). Psychiatrists who were 65 years and older were 2.6 percentage points more likely to opt out than the youngest age group, those under the age of 35 years $(p=$ 0.031). Psychiatrists who were female were 2.6 percentage points more likely to opt out of Medicare payment $(p<0.001)$. The likelihood of Medicare opt-out increased with the length of time since graduating from medical school between three and six decades from the year of graduation. Psychiatrists with 21-30 years of experience were 2.3 percentage points more likely to opt out of Medicare compared with those with a decade or less of experience $(p=0.002)$, and the likelihood of opt-out generally increased with years of experience. Psychiatrists who graduated from a top-20 ranked medical school were 1.7 percentage points more likely to opt out of Medicare $(p<0.001)$, whereas foreign medical graduates were 7.3 percentage points less likely to opt out of Medicare $(p<0.001)$.

PCSAs with a greater share of the elderly population age 75-84 were associated with lower opt-out rates than PCSAs with a greater share of the elderly age 85 and older. Practicing in a PCSA with a larger proportion of non-whites, and a larger proportion of adults with at least a college degree were associated with a greater likelihood that psychiatrist opted out of Medicare ( $p=$ 0.004 and $p=0.001$, respectively). Psychiatrists who practiced in PCSAs with higher numbers of psychiatrists per Medicare beneficiary were less likely to opt out of Medicare $(p<0.001)$. We did not find significant independent associations between psychiatrist opt-out and the proportions of Medicare beneficiaries in the area with Medicare Advantage, the proportion of Medicare beneficiaries dually eligible with Medicaid, or the adult poverty rate. 


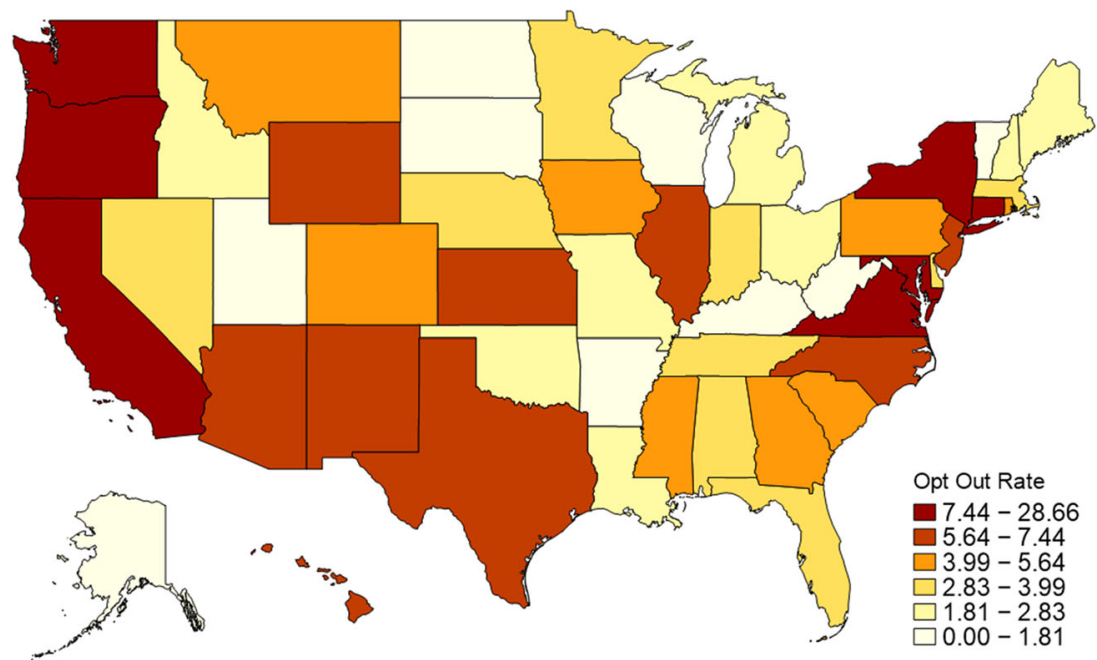

Figure 1 Psychiatrist Opt-out Rate by State. Sources: Data on opt-out status from the Center for Medicare and Medicaid Services, March 2017, CMS National Plan and Provider Enumeration System.

\section{DISCUSSION}

We examined geographic variation in the proportion of psychiatrists who opt out of Medicare, and we analyzed psychiatrist-level and geographic-level factors associated with psychiatrist opt-out of Medicare. It is already known that psychiatrists have among the highest rates of Medicare optout compared with other specialties. ${ }^{7}$ However, we found substantial variation in opt-out rates across states as well as across local health care markets within states. We identified several psychiatrist and local area characteristics independently associated with opt-out. These associations are small in absolute magnitude, but are meaningful relative to the overall low proportion of psychiatrists who opt out of Medicare.

Several of our findings are consistent with economic theory about the factors that influence physician decisions to accept Medicare patients. ${ }^{21}$ Physicians who are perceived to deliver higher quality care may be more likely to attract patients who are willing to pay higher prices for services. While years since medical school, graduating from a prestigious medical school, and being a US (vs. foreign) medical graduate are not accurate measures of quality, those characteristics may nonetheless be perceived by patients as signals of higher quality. ${ }^{22,} 23$

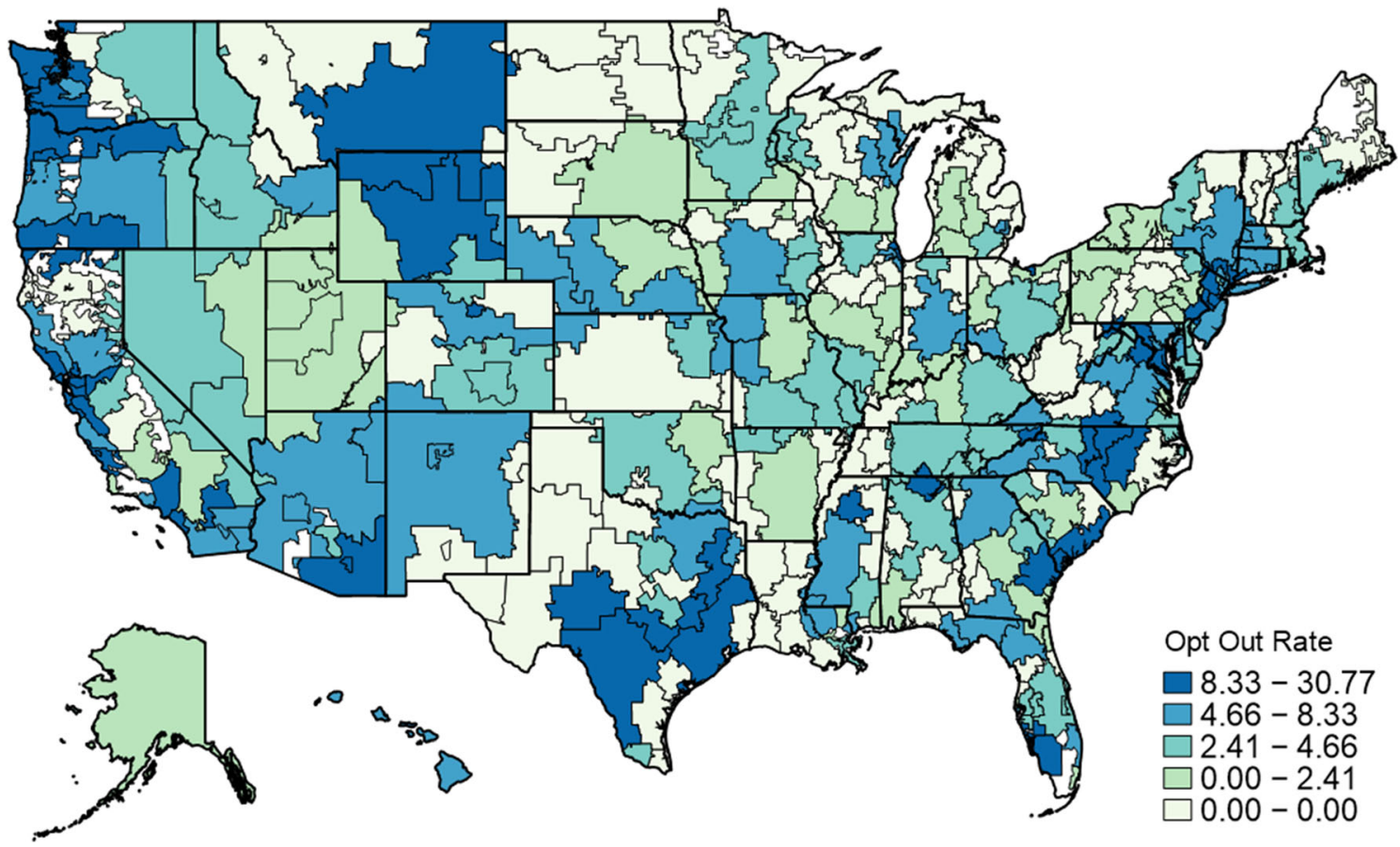

Figure 2 Psychiatrist Opt-out Rate by HRR. Sources: Data on opt-out status from the Center for Medicare and Medicaid Services, March 2017, CMS National Plan and Provider Enumeration System. 
Table 2 Average Adjusted Change in Probability of Opting out of Medicare Assignment

\begin{tabular}{|c|c|c|c|}
\hline & $\begin{array}{l}\text { Average change in probability } \\
\text { of opting out of Medicare Assignment }\end{array}$ & 95\% confidence interval & $p$ value \\
\hline \multicolumn{4}{|l|}{ Psychiatrist-level variables } \\
\hline Age: $<35$ & Ref. & & \\
\hline Age: $35-44$ & 0.007 & $-0.013,0.026$ & 0.500 \\
\hline Age: $45-54$ & 0.007 & $-0.015,0.029$ & 0.561 \\
\hline Age: $55-64$ & 0.016 & $-0.007,0.039$ & 0.167 \\
\hline Age: $65+$ & 0.026 & $0.002,0.050$ & 0.031 \\
\hline Gender-female (vs. male) & 0.026 & $0.020,0.032$ & $<0.001$ \\
\hline \multicolumn{4}{|l|}{ Decade since medical school graduation } \\
\hline 1 & Ref. & & \\
\hline 2 & 0.004 & $-0.011,0.020$ & 0.572 \\
\hline 3 & 0.023 & $0.005,0.042$ & 0.014 \\
\hline 4 & 0.031 & $0.011,0.051$ & 0.002 \\
\hline 5 & 0.034 & $0.013,0.055$ & 0.001 \\
\hline 6 & 0.039 & $0.016,0.063$ & 0.001 \\
\hline 7 & 0.024 & $-0.013,0.062$ & 0.200 \\
\hline Graduated from a top-20 medical school & 0.017 & $0.010,0.024$ & $<0.001$ \\
\hline Graduated from a foreign medical school & -0.073 & $-0.083,-0.063$ & $<0.001$ \\
\hline \multicolumn{4}{|l|}{ PCSA-level variables } \\
\hline Medicare beneficiaries in Medicare Advantage (\%) & 0.00001 & $-0.0003,0.0004$ & 0.934 \\
\hline Elderly beneficiaries between the ages of $65-74(\%)$ & -0.001 & $-0.003,0.0001$ & 0.223 \\
\hline Elderly beneficiaries between the ages of $75-84(\%)$ & -0.005 & $-0.008,-0.001$ & 0.008 \\
\hline Elderly beneficiaries aged 85 and older $(\%)$ & Ref. & & \\
\hline Non-white population $(\%)$ & 0.047 & $0.015,0.079$ & 0.004 \\
\hline Population with a Bachelor's degree - age 18 or older $(\%)$ & 0.004 & $0.003,0.005$ & $<0.001$ \\
\hline $\begin{array}{l}\text { Population living below the federal poverty level-age } 18 \text { or } \\
\text { older }(\%)\end{array}$ & 0.023 & $-0.064,0.109$ & 0.611 \\
\hline Number of psychiatrists per 100 Medicare beneficiaries & -0.013 & $-0.020,0.007$ & $<0.001$ \\
\hline \multicolumn{4}{|l|}{ HRR-level variables } \\
\hline Dual eligibles $(\%)$ & 0.0001 & $-0.001,0.001$ & 0.826 \\
\hline Number of observations & 27,838 & & \\
\hline
\end{tabular}

The table presents estimates from a mixed effects multivariable logistic regression model of Medicare opt-out, as described in the text. The estimates reflect the adjusted change in the probability of Medicare opt-out with a given change in the independent variable relative to the reference category

Similarly, practicing in an area with higher socio-economic status, as measured by the percent of the adult population with at least a bachelor's degree, may also increase opt-out rates if more patients residing in these areas are willing and able to pay psychiatrist fees that exceed Medicare fees. In addition, if there are few psychiatrists for a given population, it may be more viable to opt out of Medicare in order to request higher fees from patients. That we find no bivariate association between the number of psychiatrists per Medicare beneficiaries in a PCSA and the likelihood of opting out that is significant at the $p<0.05$ level, along with a negative independent association from the multivariable logistic regression model, suggests that psychiatrist supply is correlated with area-level characteristics such as sociodemographic characteristics, as has been demonstrated in previous research. ${ }^{24}$

Our results have several implications. First, while psychiatrists have relatively high rates of opting out of Medicare compared with other medical specialties, the vast majority of psychiatrists do accept Medicare reimbursement. As such, it is not clear how much psychiatrists opting out of Medicare contribute to welldocumented shortages of prescribing mental health professionals. ${ }^{1}$ To the extent that mental health provider shortage estimates do not take into account that some psychiatrists do not accept Medicare, one of the most important types of insurance in the USA, then, provider shortages may be more acute than has previously been reported. However, other types of physicians and non-physician mental health providers such as clinical social workers and clinical psychologists deliver the majority of mental health services in the USA. ${ }^{25}$ To the extent that these providers with prescribing authority — such as primary care physicians, physician's assistants, or nurse practitioners - can deliver mental health services of comparable quality to psychiatrists, then, psychiatrist opt-out of Medicare is not necessarily a serious policy issue. Further, broadening scopeof-practice authority, including prescribing authority, for nonphysician mental health providers may be a way to offset lack of access to psychiatrists in the Medicare program. However, psychiatrists are uniquely qualified to deliver more specialized mental health services to patients with more severe or complicated mental illness, and it is unlikely that expanding the use of primary care or non-physician providers will help improve access to care for these types of patients. Understanding how psychiatrist opt-out rates relate to measures of mental health provider shortage areas, measures of access to mental health care, and scope-ofpractice restrictions for non-physician providers is important topic for further research.

Increasing the size of the psychiatric workforce may reduce shortages of prescribing mental health providers, especially in light of our finding that more psychiatrists per Medicare beneficiary were independently associated with a lower likelihood of opting out. From 2003 to 2013, the psychiatrist workforce did not keep pace with population growth, ${ }^{24}$ and nearly all psychiatry residency slots have been filled over the past several years even as the overall number of slots has increased ${ }^{26}$ suggesting there is additional room for the psychiatry workforce to grow. If international medical graduates disproportionately fill new psychiatry 
residency slots, that may reduce Medicare opt-out as we find that international medical graduates are relatively less likely to opt out. Though not directly assessed in our analyses, raising Medicare's psychiatry payment rates, in both fee-for-service Medicare and Medicare Advantage, would presumably create incentives for physicians to enter psychiatry and reduce the incentives for psychiatrists to opt out of Medicare.

Our analyses have several limitations. First, the data are crosssectional and the results of the multivariable logistic regression analysis represent associations and not causal effects of the independent variables. Second, while the Doximity data have been used in a variety of analyses to date, ${ }^{9-12}$ the data do not include non-physician providers. Third, we lacked information on the overall payer mix of psychiatrists, including whether psychiatrists who accept Medicare reimbursement actually end up treating Medicare patients, along with the amount of uncompensated care that psychiatrists deliver. Fourth, we used existing definitions of the geographic regions where psychiatrists work. These regions were originally defined for research on inpatient services and primary care services, and we are unaware of existing definitions of markets for psychiatric services. However, in sensitivity analyses that we report in online Appendix Table 1, our main results are largely unaffected by whether we measure area characteristics at the PCSA or HRR level.

\section{CONCLUSIONS}

Relatively few psychiatrists opt out of accepting Medicare reimbursement, although the proportion opting out varies substantially by region. Psychiatrists who have more experience, who graduated from highly ranked medical schools, who are US medical graduates, who are female, and who practice in areas that have higher average educational attainment and fewer psychiatrists per Medicare beneficiary are relatively more likely to opt out of Medicare.

Corresponding Author: Ezra Golberstein, Ph.D.; Division of Health Policy and Management University of Minnesota School of Public Health, Minneapolis, MN, USA (e-mail: egolber@umn.edu).

Funding Dr. Jena received support from the Office of the Director, National Institutes of Health (DP5OD017897).

\section{Compliance with Ethical Standards:}

The study was approved as exempt from review by the institutional review board of the University of Minnesota.

Conflict of Interest: Dr. Jena received support from the Office of the Director, National Institutes of Health (DP5OD017897), and has received consulting fees unrelated to this work from Pfizer, Hill Rom Services, Bristol Myers Squibb, Novartis, Amgen, Eli Lilly, Vertex Pharmaceuticals, AstraZeneca, Celgene, Tesaro, Sanofi Aventis, Biogen, Precision Health Economics, and Analysis Group; Dr. Karaca Mandic received no support from any organization for the submitted work, and provides consulting services to Precision Health Economics that have no relation to this manuscript; all remaining authors declare that they do not have a conflict of interest.

\section{REFERENCES}

1. Thomas KC, Ellis AR, Konrad TR, Holzer CE, Morrissey JP. Countylevel estimates of mental health professional shortage in the United States. Psychiatr Serv. 2009;60:1323-1328.

2. Bishop TF, Press MJ, Keyhani S, Pincus HA. Acceptance of insurance by psychiatrists and the implications for access to mental health care. JAMA Psychiatry. 2014;71:176-181.

3. Zhu JM, Zhang Y, Polsky D. Networks in ACA marketplaces are narrower for mental health care than for primary care. Health Aff (Millwood). 2017:36:1624-1631.

4. Medicare Improvements for Patients and Providers Act of 2008. in 122 STAT 24942008.

5. Peterson E, Busch S. Achieving mental health and substance use disorder treatment parity: a quarter century of policy making and research. Annu Rev Public Health. 2018;39:421-435.

6. Bocutti C, Neuman P. Private Contracts Between Doctors and Medicare Patients: Key Questions and Implications of Proposed Policy Changes. Kaiser Family Foundation: 2017.

7. Medicare Payment Advisory Commision: March 2017 Report to the Congress: Medicare Payment Policy. 2017.

8. Centers for Medicare and Medicaid Services: Medicare Individual Provider List. 2017.

9. Jena AB, Khullar D, Ho O, Olenski AR, Blumenthal DM. Sex Differences in Academic Rank in US Medical Schools in 2014. JAMA. 2015;314:1149-1158.

10. Jena AB, Olenski AR, Blumenthal DM. Sex differences in physician salary in US Public Medical Schools. JAMA Intern Med. 2016;176:12941304.

11. Tsugawa Y, Jena AB, Orav EJ, Jha AK. Quality of care delivered by general internists in US hospitals who graduated from foreign versus US medical schools: observational study. BMJ. 2017;356:j273.

12. Tsugawa Y, Newhouse JP, Zaslavsky AM, Blumenthal DM, Jena AB. Physician age and outcomes in elderly patients in hospital in the US: observational study. BMJ. 2017:357:j1797.

13. Centers for Medicare and Medicaid Services: Medicare Provider Enrollment, Chain, and Ownership System (PECOS). 2017.

14. Kilaru AS, Wiebe DJ, Karp DN, Love J, Kallan MJ, Carr BG. Do hospital service areas and hospital referral regions define discrete health care populations? Med Care. 2015;53:510-516.

15. Goodman DC, Mick SS, Bott D, Stukel T, Chang CH, Marth N, Poage J, Carretta HJ. Primary care service areas: a new tool for the evaluation of primary care services. Health Serv Res. 2003;38:287-309.

16. US News and World Report: Best Medical Schools: Research. 2017.

17. Health Resources and Services Administration: Primary Care Service Area Data Download - 2010. U.S. Department of Health and Human Services; 2013.

18. Centers for Medicare and Medicaid Services: Public Use File. 2017.

19. US Census Bureau: American Community Survey. 2017.

20. Rabe-Hesketh S, Skrondal A. Multilevel and longitudinal modeling using Stata. 3. College Station, Stata Press; 2012

21. Sloan FA, Steinwald B. Physician participation in health-insurance plans - evidence on blue shield. J Hum Resour. 1978;13:237-263.

22. Gao GG, McCullough JS, Agarwal R, Jha AK. A changing landscape of physician quality reporting: analysis of patients' online ratings of their physicians over a 5-year period. J Med Internet Res. 2012;14:e38.

23. Reid RO, Friedberg MW, Adams JL, McGlynn EA, Mehrotra A. Associations between physician characteristics and quality of care. Arch Intern Med. 2010;170:1442-1449.

24. Bishop TF, Seirup JK, Pincus HA, Ross JS. Population of us practicing psychiatrists declined, 2003-13, which may help explain poor access to mental health care. Health Aff (Millwood). 2016;35:1271-1277.

25. Heisler EJ. The Mental Health Workforce: A Primer. Congressional Research Service; 2018

26. National Resident Matching Program: National Resident Matching Program, Results and Data: 2018 Maid Residency Match. Washington, DC2018.

Publisher's Note Springer Nature remains neutral with regard to jurisdictional claims in published maps and institutional affiliations. 